\title{
A FORTRAN IV PROGRAM FOR THE CALCULATION OF THE PETROLOGICAL NIGGLI-BARTH NORMS - A BRIEF COMMUNICATION
}

\author{
RISTO PIISPANEN
}

\begin{abstract}
PIISPANEN, R. 1977: A FORTRAN IV program for the calculation of the petrological Niggli-Barth norms - A brief communication. Bull. Geol. Soc. Finland 49: 37-38.

A computer program in FORTRAN IV for use in a time-sharing computer system has been developed to generate the Niggli-Barth norms. The paper mentions briefly the uses and limitations of the program and discusses the norms in general.
\end{abstract}

Risto Piispanen, Department of Geology, University of Oulu, SF-90100 Oulu 10, Finland.

Several kinds of norms exist in petrology and geochemistry, those favored by the American and British geologists originate from Cross, Iddings, Pirsson and Washington (1903). The CIPW norms have subsequently been modified in a variety of ways so that hardly any of the proposed methods of calculating them are exactly alike. Computer programs have also been developed for the various ways of calculating the CIPW norms (e.g. Jung and Schulz 1965). In Scandinavia the norm system originating from Niggli (1936) and later modified at several points by Barth is used in its latest form as outlined by Barth in 1962. Wedepohl (1969) calls these norms the Niggli-Barth norms, the name which is also adopted here. No published computer program exists to date for these norms, to the best of the author's knowledge.
Since the space does not permit reproduction of the entire program, nor of its flow chart or accompanying program description, only the main characteristics can be given in this context. Those interested in obtaining the program list, flow chart and step-by-step description can do so from the writer at a charge thought reasonable to cover duplication costs.

The program utilizes the instructions given by Barth (1962, pp. 67-69) with some necessary but self-explanatory deviations. For example, ferrous iron and manganese are combined and stored under ferrous iron. Likewise in cases of exceptionally high figures for sulphur, carbon dioxide, phosphorus or titania the machine is programmed to report these excesses and to stop the calculation there and proceed to the next analysis. 
The program suffers from the same limitations as the Niggli-Barth norms in general. The program, as already stated, refuses to calculate the norms in a case where the carbon dioxide figure is high, for instance, not necessarily because of an analytical error, but because of the fact that there must be dolomite or ankerite in the rock.

In the case of alkaline rocks several complications arise. It is common for there to be an excess of titania over the ferrous iron in the form of perovskite, for instance, ard consequently the system lacks instruction as to how to proceed in such cases. Experiments performed with the program on alkaline rocks also showed that wollastonite should be treated as an independent normative mineral in order to obtain meaningful results, for a negative sign is gained for orthopyroxene if it is combined with all of the wollastonite to form diopside. Another minor inconsistency and a weak point of the system is revealed as soon as the norms are calculated for a rock extremely poor in silica. In an olivinemelilitite (Wedepohl 1969, p. 239, no. 15b) even the formation of kaliophilite is insufficient to maintain the silica balance and as a result a negative sign is gained for quartz. The system lacks instructions for such cases and thus the program fails to calculate the correct norms.

The program can be used conveniently in teaching petrology, for instance, and is very instructive for experimentation on the effects on the norms of small intentional changes made in the analysis figures. The student can, for example, try to locate the narrow limits in composition between the olivine normative and the quartz normative rocks.

\section{References}

Barth, T. F. W. (1962) Theoretical Petrology. 2nd ed. J. Wiley \& Sons.

Cross, W., Iddings, J. P., Pirsson, L. V. and Washington, H. S. (1903) Quantitative Classification of Igneous Rocks. Univ. of Chicago Press, Chicago.

Jung, D. and Schulz, H. (1965) Beschreibung von Algol-Programmen zur Berechnung der
NIGGLI-Werte und der CIPW-Norm. N. Jb. Min. Abh. 103 (3): 256-272.

Niggli, P. (1936) Über Molekularnormen zur Gesteinsberechnung. Schweizer. Min. Petr. Mitt. 16: $295-317$.

Wedepohl, K. H. (ed.) (1969) Handbook of Geochemistry. Vol. I. Springer-Verlag.

Manuscript received, September 23, 1976. 